\title{
МАНИФЕСТАЦИЯ САХАРНОГО ДИАБЕТА 1 ТИПА У ДЕТЕЙ И ПОДРОСТКОВ, ПРОЖИВАЮЩИХ В ЗАКРЫТОМ АДМИНИСТРАТИВНО-ТЕРРИТОРИАЛЬНОМ ОБРАЗОВАНИИ (ЗАТО) НА ТЕРРИТОРИИ КРАСНОЯРСКОГО КРАЯ
}

\author{
М.В. Проскурина', Т.Е. Таранушенко ${ }^{2}$, Н.Г. Киселева ${ }^{2}$, А.Н. Наркевич ${ }^{2}$ \\ 1 1ФГБУЗ КБ № 51 ФМБА России, г. Красноярск. \\ 2ФГБОУ ВО «Красноярский государственный медицинский университет \\ им. проф. В.Ф. Войно-Ясенецкого»МЗ.
}

\begin{abstract}
АКТУАЛЬНОСТЬ. Сахарный диабет 1 типа (СД1) у детей и подростков остается одной из актуальных проблем мирового медицинского сообщества. Сложность ситуации подтверждается постоянным ростом количества вновь заболевших детей. В данном аспекте становится важным изучение этапа манифестации заболевания, подробное рассмотрение факторов, сопутствующих инициации процесса, и дальнейшее развитие знаний по профилактике и максимальному отсрочиванию дебюта заболевания.

Настоящая работа по исследованию особенностей манифестации СД1 среди детей и подростков проводилась впервые в закрытом административно-территориальном образовании (ЗАТО) на территории Красноярского края.

ЦЕЛЬ - изучить особенности дебюта СД1 среди детей и подростков, проживающих на территории ЗАТО, на основе данных анамнеза, гендерного состава и возраста заболевших, сезонности заболеваемости, а также клинических проявлений и показателей углеводного обмена на этапе манифестации (при первичном обращении к эндокринологу).
\end{abstract}

МАТЕРИАЛЫ И МЕТОДЫ. Настоящее исследование проведено на базе ФГБУЗ КБ № 51 ФМБА России, филиала ФГБУ ФСНКЦ ФМБА России КБ № 42.

В работе представлены данные сплошного когортного ретроспективного исследования с анализом анамнестических и клинико-лабораторных данных детей с СД1, диагностированным за период с 2009 по 2019 гг. Группу наблюдения составили 55 детей от 0 до 18 лет, страдающие СД1а и постоянно проживающие на территории ЗАТО. Все данные о пациентах собраны в соответствии с протоколом настоящего исследования, включая сведения регионального регистра сахарного диабета, историй болезни (форма № 003/y) и амбулаторных карт (форма 025 /у-0).

Исследование выполнено в соответствии с унифицированным протоколом, включающим необходимые сведения о каждом ребенке (паспортные данные, анамнез жизни и заболевания, жалобы, результаты клинико-лабораторных исследований (в том числе гликемия натощак, гликемия постпрандиальная, среднесуточная гликемия, средняя амплитуда колебания гликемии, гликированный гемоглобин) при первичном обращении к эндокринологу. За диагностический критерий принят уровень глюкозы натощак в плазме венозной крови свыше 6,3 ммоль/л, уровень $\mathrm{HbA}_{1 c^{\prime}}$ превышающий 6\%. Исследование одобрено Этическим комитетом ГОУ ВПО КрасГМУ (выписка из протокола №7 заседания локального этического комитета от 06.06.2018 г.).

Анализ показателей проводился как в целом по когорте, так и в возрастных группах, которые традиционно приняты для педиатрической практики.

Статистическая обработка результатов исследования выполнена с помощью пакета прикладных программ IBM SPSS STATISTICS v. 19. Результаты представлены в виде $M \pm \sigma$, где $M-$ среднее значение, $\Sigma$ - стандартное отклонение, медианы Ме (25 и 75 перцентили). Методы статистического анализа выбирались после определения соответствия выборок закону нормального распределения с учетом теста Шапиро-Уилка. Учитывая отклонения выборок от нормального распределения в сравнительном анализе использовались непараметрические критерии ( $\chi^{2}$, Манна-Уитни либо критерий Уилкоксона для зависимых групп). Различия считались статистически значимыми при значениях $\mathrm{p}<0,05$. Рассчитаны средние значения, медиана полученных показателей.

РЕЗУЛЬТАТЫ: анализируемая группа пациентов включила детей от 0 до 18 лет с выделением подгрупп с учетом возрастных и гендерных признаков. Средний возраст по группе на момент дебюта составил 8,4 года, Ме 9 лет [97\% ДИ 1,45-16]. 


\section{СБОРНИК ТЕЗИСОВ}

XVII Российская научно-практическая конференция детских эндокринологов «Достижения науки в практику детского эндокринолога»

Известно, что в развитии сахарного диабета участвуют генетические факторы, которые реализуются под влиянием различных внешних воздействий. Так в соответствии с литературными источниками наследственный риск развития СД1 у детей составляет 1,1\%. По нашим данным в рассматриваемой группе указания на отягощенный семейный анамнез по инсулинозависимому сахарному диабету отмечены у 9,1\% детей. В 90,9\% случаях заболевание рассматривалось как спорадическая форма. Полученные данные совпадают с общероссийскими тенденциями, а также с ранее полученными данными по Красноярскому краю, согласно которым только 13,1\% пациентов имели родственников с СД1.

Дискутируется вопрос о взаимосвязи возраста родителей с вероятностью развития СД1. По данным настоящего исследования средний возраст матерей на момент рождения детей составил 28,7 года, Ме - 28 лет [97\% ДИ 18-38], при этом возраст матерей на момент рождения ребенка показал обратную зависимость с возрастом манифестации заболевания у ребенка.

По результатам нашего наблюдения, в $18,1 \%$ случаев один из родителей заболевшего работал на градообразующем предприятии (более 5 лет до рождения ребенка), что не исключает опосредованное воздействие антропогенных факторов на формирование патологии и согласуется с литературными данными о влиянии внешних факторов (инфекционные, физические и/или химические воздействия), способных запускать эпигенетические и иммуноопосредованные механизмы различной патологии.

Оценка возрастных аспектов манифестации показала следующее: в рассматриваемой когорте пациентов наиболее часто заболевания диагностировалось впервые в возрастных группах 5-9 лет и 10-14 лет, что соответственно составило 41,8\% и 34,5\% от общего числа больных. Полученные результаты сопоставимы с данными Российской Федерации и отдельных регионов России (Тверская область, Красноярский край и др.). Принадлежность впервые заболевших детей к указанным возрастным группам может быть обусловлена пре- и пубертатными особенностями этого периода в жизни ребенка. Известно, что в этом возрасте организм подростка претерпевает вегетативные, эндокринные и иммунные перестройки, что повышает риск развития психосоциальной дезадаптации и дизрегуляторных нарушений с лабильностью гоместаза, присоединением функциональных нарушений и, не редко, формированием новых патологических состояний.

Манифестации диабета в рассматриваемых возрастных группах детей не имела существенных гендерных различий, т.е. в пре- и пубертатные периоды заболевание развивалось с примерно одинаковой частотой как мальчиков, так и девочек. Исключение составила подгруппа детей, заболевших в раннем возрасте (0-4 года), где преобладали девочки, а с 10-14 лет - мальчики. При уточнении гендерных особенностей диабета в остальных возрастных подгруппах не выявлено значимых различий между мальчиками и девочками.

Анализ особенностей манифестации СД1 с учетом сезонов года показал, что дебют заболевания в большинстве случаев приходился на весенний и осенний периоды года, соответственно $29,1 \%$ и 34,5\% от всех зарегистрированных случаев. Представленные данные не в полной мере совпадают с результатами других исследователей, но общим для большинства публикаций является указание на более низкую выявляемость случаев СД в летнее время. По известным литературным данным манифестация диабета в высокой степени вероятности ассоциирована с сезонными пиками острых респираторных инфекций в холодное время года. Оценка причинных факторов, возможно провоцирующих манифестацию СД1, на основе анализа, который был проведен в Эндокринологическом научном центре РАМН в 1999 г. и показал, что у 58,7\% детей за 6-10 мес до дебюта диабета отмечалась вирусная инфекция, у 5,6\% - наиболее вероятным провоцирующим фактором был стресс, и у 22,6\% заболевших причина осталась неуточненной. В нашем исследовании среди факторов, которые предшествовали заболеванию за несколько месяцев, острые респираторно вирусные инфекции зарегистрированы в 18,1\% случаев, значимые стрессовые ситуации отмечены в 10,9\% наблюдений. Манифестация СД1 типа на фоне инфекционной патологии (ИМВП, парапроктит и др.) установлена у 10,9\% детей. До настоящего времени триггерные факторы в реализации диабета остаются малопонятными и непроясненными. 
Известно, что интегральным показателем соматического благополучия ребенка являются антропометрические показатели. Нами выполнена оценка физического развития детей и подростков на момент дебюта диабета. Гипотетически можно предполагать, что дефицит инсулина может ухудшить массо-ростовые характеристики заболевших детей. Однако только в одном случае физическое развитие было ниже среднего, среднее развитие имели 76,36\% и выше среднего 21,8\% от всей наблюдаемой когорты. При оценке физического развития с учетом ИМТ отмечено, что основная часть детей (56,3\% от всех наблюдений) на момент дебюта имели гармоничное развитие. С одинаковой частотой регистрировались случаи с пониженным и повышенным питанием по 12,7\% соответственно. У 18,1\% пациентов манифестация СД1т сопровождалась белково-энергетической недостаточностью с дефицитом массы более $10 \%$.

Известно, что СД1 ассоциирован с аутоиммунным разрушением $\beta$-клеток поджелудочной железы, которое происходит с разной интенсивностью, а клинические симптомы и выраженные лабораторные изменения появляются при разрушении около 90\% $\beta$-клеток поджелудочной железы. По нашим данным при первичном обращении у всех детей присутствовали типичные жалобы (жажда, частые мочеиспускания, похудение) в разной степени выраженности. Лабораторные показатели гликемии по данным первичного обращения с вышеуказанными жалобами: среднее значение по группе составило 19,8 ммоль/л с максимальным примерно одинаковым значением в группе детей от 5-7лет и группе подростков. Полученное значение существенно превышает диагностический показатель при манифестации СД1. Высокие значения постпрандиальной гликемии составили 19,9 ммоль/л и повышенный гликированный гемоглобин (средние значения $\left.\mathrm{HbA}_{1 c}-10,6 \%\right)$ свидетельствуют о выраженной декомпенсации диабета на момент дебюта. При оценке углеводного обмена на момент манифестации в рассматриваемых возрастных подгруппах наиболее значительная гипергликемия натощак отмечена в пубертатном возрасте, постпрандиальная гипергликемия не имела существенных отличий в представленных возрастных группах. Более высокие средние показатели гликозилированного гемоглобина установлены у детей предподросткового и подросткового возраста.

ЗАКЛЮЧЕНИЕ: результаты выполненного исследования позволяют обозначить анамнестические и клинико-лабораторные особенности дебюта инсулинозависимого сахарного диабета у детей. Полученные данные подтверждают низкую диагностическую значимость указаний на отягощенную наследственность по сахарному диабету, возможное влияние возраста матери к моменту рождения ребенка на срок манифестации (возраст дебюта) болезни у ребенка.

Выполненное исследование не установило гендерных отличий, но показало преобладание девочек среди заболевших в раннем возрасте (0-4 лет и мальчиков от 10 до 14 лет). Наибольший процент случаев впервые диагностированного диабета отмечен в пре- и пубертатный период.

Наиболее значимыми (возможно инициирующими) факторами, предшествующими манифестации сахарного диабета, были острые респираторные вирусные инфекции и перенесенные стрессовые ситуации. К сезонным особенностям манифестации Сд1 отнесена более высокая заболеваемость в весенне-осенний период года.

Показатели углеводного обмена на момент дебюта говорили о выраженной декомпенсации, максимальные показатели $\mathrm{HbA}_{1 с}$ выявлены в предподростковой и подростковой группе. При сравнении возрастных групп обнаружено достоверное отличие начальной гликемии у детей в группе 0-4 лет и 5-7 лет. 